\title{
MicroRNA-146a affects the chemotherapeutic sensitivity and prognosis of advanced gastric cancer through the regulation of LIN52
}

\author{
ZHIFEN LUO $^{1 *}$, XIQING LI $^{1 *}$, ZUNLAN ZHAO $^{1}$, XINGLONG YANG $^{2}$, SHENGJUN XIAO $^{3}$ and YUN ZHOU ${ }^{1}$ \\ ${ }^{1}$ Department of Oncology, Henan Provincial People's Hospital, Zhengzhou, Henan 450003; ${ }^{2}$ Cancer Institute, \\ Southern Medical University, Guangzhou, Guangdong 510515; ${ }^{3}$ Department of Pathology, \\ Hospital of Guilin Medical University, Guilin, Guangxi 541001, P.R. China
}

Received July 15, 2015; Accepted November 7, 2016

DOI: $10.3892 / 01.2016 .5536$

\begin{abstract}
The present study aimed to evaluate the correlation between the expression of microRNA-146a (miR-146a) and its target gene, LIN52, in advanced gastric cancer, and determine their potential effects on chemotherapeutic sensitivity and prognosis. Total RNA was extracted from 93 tissue samples of advanced gastric cancer and corresponding adjacent non-tumor tissues to quantify the relative expression levels of miR-146a using reverse transcription-quantitative polymerase chain reaction analysis. The expression of LIN52 was detected in tumors and normal tissues using immunohistochemical analysis. Correlation analysis was performed to assess the correlation between the expression of miR-146a and LIN52 and clinicopathological parameters of gastric cancer, including clinical diagnostic specificity, clinical tumor-necrosis-metastasis staging, lymph node metastasis, differentiation grade, chemotherapeutic sensitivity and prognosis. The expression of miR-146a in advanced gastric cancer tissues was lower, compared with that in the adjacent non-tumor tissues, and was negatively correlated with lymph node metastasis $(\mathrm{P}<0.05)$. Gastric cancer tissues with a low expression level of miR146a exhibited an increased expression level of LIN52 $(\mathrm{P}<0.05)$. Receiver operating characteristic curve regression analysis showed that miR-146a had $98 \%$ sensitivity in distinguishing gastric cancer tissues and adjacent non-tumor tissues. A high expression of miR-146a in gastric cancer was associated with improved treatment efficacy in patients. The chemotherapeutic sensitivity of patients with tumors expressing high levels of
\end{abstract}

Correspondence to: Dr Zhifen Luo, Department of Oncology, Henan Provincial People's Hospital, 7 Weiwu Road, Zhengzhou, Henan 450003, P.R. China

E-mail: luozhifen123@126.com

*Contributed equally

Key words: microRNA-146a, LIN52, advanced gastric cancer, chemotherapeutic sensitivity, diagnosis, lymph node metastasis
miR-146a was significantly higher, compared with that of patients with tumors expressing low levels of miR-146a $(\mathrm{P}<0.05)$. The expression of miR-146a was low in advanced gastric cancer tissues. As a tumor suppressor gene in advanced gastric cancer, miR-146a had a significant negative correlation with LIN52. High expression levels of miR-146a in advanced gastric cancer tissue may be associated with improved treatment efficacy of chemotherapy, suggesting that miR-146a may be a molecular marker for the diagnosis, prediction of treatment efficacy and prognosis of advanced gastric cancer.

\section{Introduction}

Gastric cancer is a common malignancy affecting the gastrointestinal system, which accounts for $8 \%$ of all types of malignant cancer. Although the incidence of gastric cancer has been declining worldwide, it remains high in several countries, particularly in China (1). The development and progression of gastric cancer are associated with multiple genes and numerous transforming steps. Investigating genetic and other risk factors associated with the occurrence and development of gastric cancer, and their correlation with prognosis, is critical to provide theoretical support for improving the diagnosis, prognosis and treatment of gastric cancer (2). MicroRNAs (miRs) are small non-coding RNA molecules of 22 nucleotides, which regulate gene expression at the post-transcriptional level. The regulatory capacity of miRs includes almost all major cellular activities, including cell proliferation, differentiation and apoptosis. In previous years, a number of studies have shown that microRNAs can have oncogene and tumor suppressor functions, thereby being involved in tumor development and progression (3-5). A previous study showed that miR-146a was associated with gastric cancer metastasis through modulating Wiskott-Aldrich syndrome protein family member 2 (6). Other studies have shown that the expression of miR-146a is associated with tumor cell proliferation and apoptosis in gastric cancer $(7,8)$. miR-146a has direct effects on tumor metastasis and prognosis by affecting epidermal growth factor receptor (EGFR) (8). The expression of LIN52 in gastrointestinal tumors affects drug sensitivity and enhances the effect of imatinib-induced apoptosis in tumor cells (9). In 
addition, according to the predictions of TargetScan, miR-146a is a target gene regulated by LIN52 (10). The present study further analyzed the effect of miR-146a on the treatment of gastric cancer. The expression of miR-146a was analyzed in 93 clinical cases of advanced gastric cancer using reverse transcription-quantitative polymerase chain reaction (RT-qPCR) analysis, and its expression was correlated with the clinical characteristics of advanced gastric cancer and the prognosis of patients.

\section{Materials and methods}

Patients and sampling. A total of 93 patients with advanced gastric cancer (57 men and 36 women; median age, 61 years), who underwent surgical treatment between June 2009 and January 2011 in Henan Provincial People's Hospital (Henan, China) were enrolled in the present study. All patients received an oxaliplatin-based chemotherapeutic regimen following surgical treatment, and the efficacy was evaluated in accordance with the Response Evaluation Criteria in Solid Tumors (RESIST) (11) The histopathological analysis of resected tissues was based on the tumor-node-metastasis (TNM) staging criteria of the World Health Organization (11). From each patient, non-tumor tissues were collected $7 \mathrm{~cm}$ adjacent to the tumor lesion as an internal control. The histological sections of each resected specimen were classified by pathologists. All patients signed written informed consent prior to their involvement in the study. The experimental protocol of the present study was approved by the Ethics Committee of Henan Provincial People's Hospital.

Reagents. Mouse anti-human LIN52 monoclonal antibody was purchased from Santa Cruz Biotechnology, Inc. (Dallas, TX, USA). The streptavidin-peroxidase (SP) immunohistochemical staining kit and 3,3'-diaminobenzidine (DAB) peroxidase substrate kit were purchased from Fuzhou Maxim Biotech, Inc. (Fujian, China). The experimental procedures for the immunohistochemistry were according to the protocol of the SP staining kit manufacturer. Phosphate-buffered saline (PBS) with Tween detergent was used to replace primary antibody in the negative control for the immunohistochemistry assays. TRIzol reagent was purchased from Thermo Fisher Scientific, Inc. (Waltham, MA, USA). The reverse transcription kit (K1622 MBI) was purchased from Fermentas; Thermo Fisher Scientific, Inc. SYBR ${ }^{\circledR}$ Green PCR Master Mix was purchased from Takara Bio, Inc. (Otsu, Japan). The Stratagene Mx3005P RT-qPCR instrument was purchased from Agilent Technologies, Inc. (Santa Clara, CA, USA). Other conventional reagents for molecular biology were purchased from Sigma-Aldrich (Merck Millipore, Darmstadt, Germany).

Immunohistochemistry. Following conventional tissue processing, paraffin-embedding and sectioning, each tissue section was dewaxed and hydrated in water, followed by incubation with $3 \%$ hydrogen peroxide at room temperature for $15 \mathrm{~min}$ and high pressure antigen retrieval for $2 \mathrm{~min}$. Following cooling of the sections to room temperature, each section was blocked in normal goat serum (Fuzhou Maxim Biotech, Inc.) at room temperature for $10 \mathrm{~min}$, and incubated with LIN52 antibody (dilution, 1:300) at $4^{\circ} \mathrm{C}$ overnight. Each tissue section was then incubated with biotinylated rabbit anti-mouse secondary antibody (Santa Cruz Biotechnology, Inc.) at $37^{\circ} \mathrm{C}$ for $10 \mathrm{~min}$. Following washing of the tissue sections with PBS, DAB solution was used for color development, followed by repeated washing under tap water and hematoxylin counterstaining. Excess dye from the tissue sections was removed using hydrochloric acid. All tissue sections were dehydrated in graded ethanol solutions and cleared in xylene solution prior to mounting on glass slides using neutral gum. A light microscope was used to visualize staining.

RT-qPCR analysis. Following collection of the resected tissue and snap freezing in liquid nitrogen, each tissue specimen was crushed into a powder, followed by total RNA extraction. TRIizol reagent $(1 \mathrm{ml})$ was added to the tissue powder to lyse the cells for $10 \mathrm{~min}$, followed by transfer of the supernatant to a microcentrifuge tube. Chloroform solution (400 $\mu \mathrm{l})$ was added to the supernatant, vortexed and subjected to $12,000 \mathrm{~g}$ centrifugation at $4^{\circ} \mathrm{C}$ for $15 \mathrm{~min}$. The supernatant $(200 \mu \mathrm{l})$ was then transferred to a new RNase-free microcentrifuge tube and mixed with equal quantities of isopropanol by inverting the tube, followed by incubation for $10 \mathrm{~min}$ and $12,000 \mathrm{~g}$ centrifugation at $4^{\circ} \mathrm{C}$ for $10 \mathrm{~min}$. The supernatant was discarded, followed by the addition of $1 \mathrm{ml} \mathrm{70 \%} \mathrm{ethanol} \mathrm{to} \mathrm{the} \mathrm{pellet} \mathrm{and} \mathrm{mixing} \mathrm{by}$ gentle inversion of the microcentrifuge tube. The mixture was centrifuged at $12,000 \mathrm{~g}$ at $4^{\circ} \mathrm{C}$ for $10 \mathrm{~min}$, following which the ethanol solution was discarded and the pellet was air-dried. The pellet was then dissolved in diethyl pyrocarbonate-treated distilled water. The total RNA concentration of each sample was determined using an e-Spect ultra-small spectrophotometer (Malcom Co., Ltd., Tokyo, Japan). The RNA quality of each sample was determined based on the optical density (OD) 260/280 ratio, ranging between 1.8 and 2.0. For cDNA synthesis, $20 \mu \mathrm{l}$ reverse transcriptase solution from the kit was added to $0.1 \mu \mathrm{g}$ RNA template, miR-146a reverse primer and U6 primer for reverse transcription into cDNA. U6 was the internal reference for analysis of the expression of miR-146a. Details of the primers are listed in Table I. The primers and RNA template were incubated at $65^{\circ} \mathrm{C}$ for $5 \mathrm{~min}$, followed by cooling on ice, incubation with the reverse transctiption reaction mixture and dNTPs at $42^{\circ} \mathrm{C}$ for $60 \mathrm{~min}$, and termination of the reaction at $70^{\circ} \mathrm{C}$ for $5 \mathrm{~min}$. The total volume of master mix for the qPCR analysis was $20 \mu \mathrm{l}$, containing $1 \mu \mathrm{l}$ of cDNA (final concentration $5 \mathrm{ng}$ ), $12.5 \mu \mathrm{l}$ of $2 \mathrm{X}$ SYBR Green I Master mix, $0.5 \mu \mathrm{mol} / 1 \mathrm{miR}-146 \mathrm{a} / \mathrm{U} 6$ specific forward primers and $0.5 \mu \mathrm{mol} / 1 \mathrm{miR}-146 \mathrm{a} / \mathrm{U} 6$ reverse primers. Each sample had three replicates. The qPCR conditions were as follows: $95^{\circ} \mathrm{C}$ for $7 \mathrm{~min}$, followed by 40 cycles of denaturation at $95^{\circ} \mathrm{C}$ for $15 \mathrm{sec}$, annealing at $60^{\circ} \mathrm{C}$ for $25 \mathrm{sec}$ and elongation at $72^{\circ} \mathrm{C}$ for $25 \mathrm{sec}$. The quantification cycle $(\mathrm{Cq})$ value of the $\mathrm{U} 6$ reaction obtained from the qPCR analysis was used to calculate the $\mathrm{Cq}$ value representing the relative expression of miR-146a. qPCR was activated at $95^{\circ} \mathrm{C}$ for $5 \mathrm{~min}$, followed by 45 cycles of denaturation at $95^{\circ} \mathrm{C}$ for $15 \mathrm{sec}$, annealing at $62^{\circ} \mathrm{C}$ for $30 \mathrm{sec}$ and elongation at $72^{\circ} \mathrm{C}$ for $20 \mathrm{sec}$. The $\mathrm{Cq}$ value, standard and melting curves were automatically generated by the RT-qPCR instrument.

Statistical analysis. SPSS 13.0 software was used for the non-parametric rank sum test. Relative expression $\geq 2.0$ was 
Table I. miR-146a and U6 primer sequences for reverse transcription-quantitative polymerase chain reaction analysis.

\begin{tabular}{ll}
\hline Primer & \multicolumn{1}{c}{ Sequence } \\
\hline miR-146a & \\
RT & 5'-CTCAACTGGTGTCGTGGAGTCGGCAATTCAGTTGAGAACCCATG-3' \\
Forward & 5'-TGGTGTCGTGGAGTCG-3' \\
Reverse & 5'-ACACTCCAGCTGGGTGAGAACTGAATTCCATGGGTT-3' \\
U6 & \\
Forward & 5'-CTCGCTTCGGCAGCACA-3' \\
RT and reverse & 5'-AACGCTTCACGAATTTGCGT-3' \\
\hline
\end{tabular}

miR, microRNA; RT, reverse transcription.
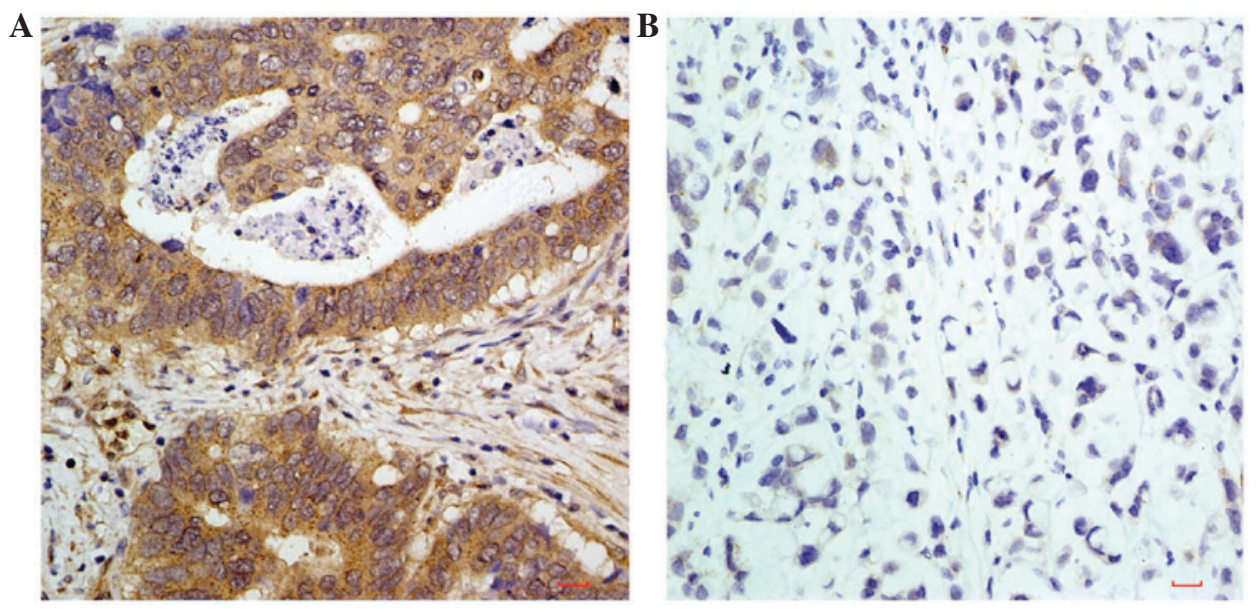

Figure 1. Representative images of LIN52 immunohistochemical staining in the cytoplasm of (A) gastric cancer tissue and (B) adjacent normal tissue (magnification, $\mathrm{x} 400)$. Scale bar $=10 \mu \mathrm{m}$.

defined as high expression and relative expression $<2.0$ was defined as low expression following Kaplan-Meier survival analysis. The Cox regression model was based on the forward method of conditional parameter estimates. $\mathrm{P}<0.05$ was considered to indicate a statistically significant difference.

\section{Results}

Positive protein expression of LIN52. As shown in Fig. 1A, positive staining of the LIN52 protein, identified as brownish yellow granules, was distributed predominantly in the cytoplasm of the advanced gastric cancer tissues. In the normal tissues adjacent to the tumor, the expression of LIN52 was low (Fig. 1B).

Correlation between the expression of miR-146a in advanced gastric cancer tissues and clinicopathological parameters. The expression of miR-146a in the advanced gastric cancer tissue was significantly correlated with the clinical TNM staging of the patients $(\mathrm{P}<0.05)$. The expression of miR-146a in stage III gastric cancer tissues was significantly higher, compared with that in stage IV gastric cancer tissues $(\mathrm{P}<0.05)$. Patients with lymph node metastasis had lower expression levels of miR-146a, compared with patients without lymph node metastasis. However, no significant correlation was found between the expression of miR-146a in advanced gastric cancer tissue and other clinicopathological factors, including gender, age and tumor differentiation ( $\mathrm{P}>0.05$; Table II).

Correlation between the expression of miR-146a and patient survival rates. The results of the Kaplan-Meier survival analysis showed that the expression of miR-146a had a significant effect on the survival rates of patients with advanced gastric cancer. Patients with high expression levels of miR-146a had significantly higher survival rates, compared with patients with low expression levels of miR-146a ( $\mathrm{P}<0.05$; Fig. 2).

Correlation between the expression levels of miR146a and LIN52 in advanced gastric cancer. The present study further analyzed the correlation between the expression levels of miR146a and LIN52. Among the 44 specimens with a high expression of miR146a, only 8 (18.2\%) showed LIN52 immunoreactivity $(\mathrm{P}<0.001$; Table III).

Cox regression analysis of prognostic factors in patients with gastric cancer. The clinical prognostic factors of patients with advanced gastric cancer were used as dependent variables and their relevant effects were used as independent variables for Cox regression analysis. As shown in Table IV, TNM staging, lymph node metastasis and the expression of miR-146a were 
Table II. Expression of miR-146a and LIN52 in 93 patients with gastric cancer and their correlation with clinicopathological parameters.

\begin{tabular}{|c|c|c|c|c|c|c|c|}
\hline \multirow[b]{2}{*}{ Parameter } & \multirow[b]{2}{*}{$\mathrm{n}$} & \multicolumn{3}{|c|}{ miR-146a, n (\%) } & \multicolumn{3}{|c|}{ LIN52, n (\%) } \\
\hline & & Low & High & P-value ${ }^{a}$ & Low & High & P-value \\
\hline Gender & & & & 0.091 & & & 0.077 \\
\hline Male & 57 & $34(59.6)$ & $23(40.4)$ & & $29(53.7)$ & $25(46.3)$ & \\
\hline Female & 36 & 15 (41.7) & $21(58.3)$ & & $28(71.8)$ & $11(28.2)$ & \\
\hline Age (years) & & & & 0.350 & & & 0.484 \\
\hline$<56$ & 32 & $19(59.4)$ & $13(40.6)$ & & $18(56.3)$ & $14(43.8)$ & \\
\hline$\geq 56$ & 61 & $30(49.2)$ & $31(50.8)$ & & $39(63.9)$ & $22(36.1)$ & \\
\hline Grade & & & & 0.295 & & & 0.519 \\
\hline Poorly differentiated & 18 & $13(72.2)$ & $5(27.8)$ & & $5(27.8)$ & $13(72.2)$ & \\
\hline Moderately differentiated & 33 & $17(51.5)$ & $16(48.5)$ & & $15(45.5)$ & $18(54.5)$ & \\
\hline Well differentiated & 22 & $10(45.5)$ & $12(54.5)$ & & $11(50.0)$ & $11(50.0)$ & \\
\hline Signet-ring cell carcinoma & 20 & $9(45.0)$ & $11(55.5)$ & & $8(40.0)$ & $12(60.0)$ & \\
\hline Lymph node metastasis & & & & 0.033 & & & 0.754 \\
\hline Present & 76 & $44(57.9)$ & $32(42.1)$ & & $39(59.1)$ & $27(40.9)$ & \\
\hline Not present & 17 & $5(29.4)$ & $12(70.6)$ & & $15(55.6)$ & $12(44.4)$ & \\
\hline Clinical stage & & & & 0.011 & & & 0.051 \\
\hline III & 42 & $16(38.1)$ & $26(61.9)$ & & $29(69.0)$ & $13(31.0)$ & \\
\hline IV & 51 & $33(64.7)$ & $18(35.3)$ & & $25(49.0)$ & $26(51.0)$ & \\
\hline
\end{tabular}

${ }^{2} \chi^{2}$ test. miR, microRNA.
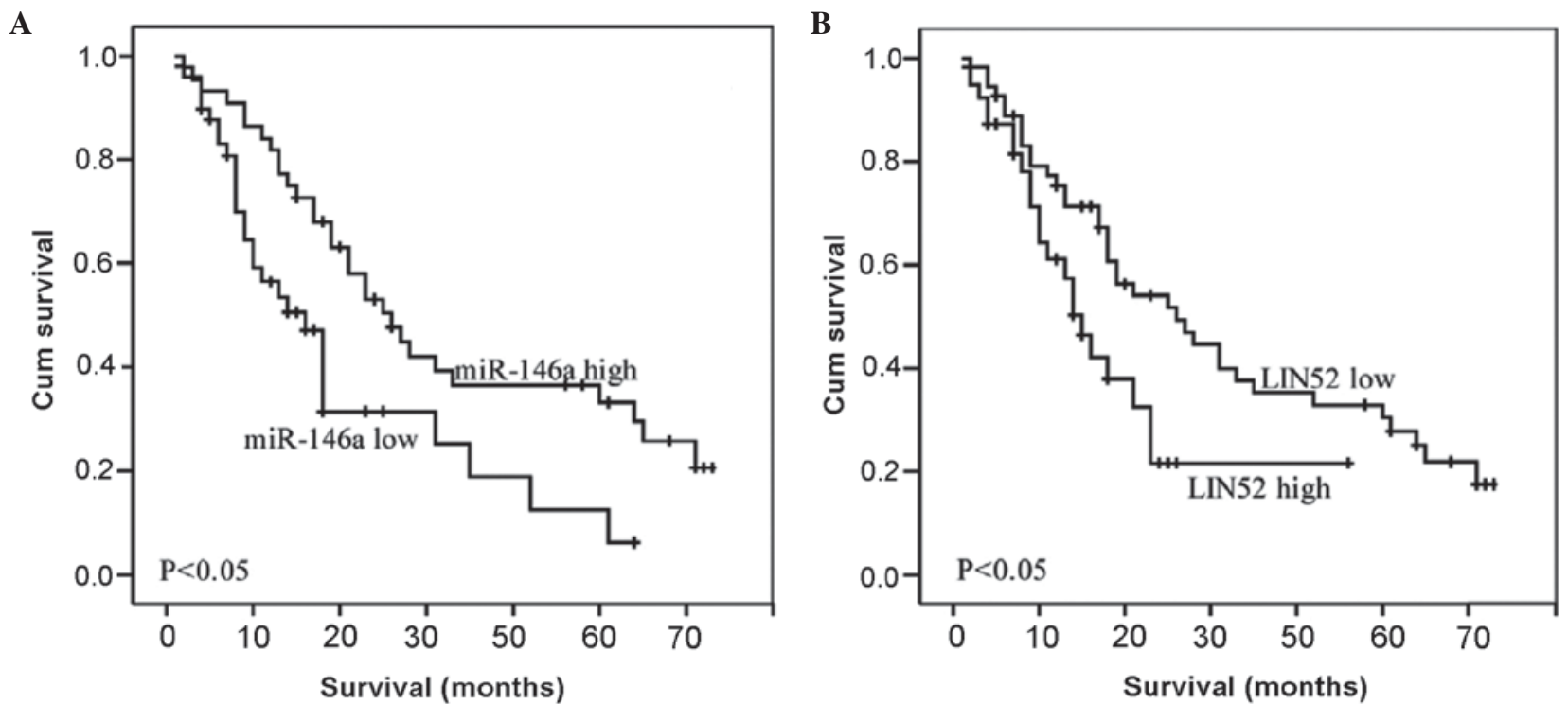

Figure 2. Kaplan-Meier analysis of survival rates of patients according to miR-146a and LIN52 expression status. The effects of the expression of (A) miR146a and (B) LIN52 on the prognosis of patients with gastric cancer are shown. miR, microRNA.

independent risk factors for the prognosis of patients with advanced gastric cancer.

Expression of miR-146a and chemotherapeutic sensitivity. The present study also assessed the association between the expression of miR-146a and chemotherapeutic sensitivity in patients with advanced gastric cancer. The analysis showed that patients with advanced gastric cancer tissues expressing a low level of miR-146a had a poor prognosis (Fig. 3). The present study evaluated the efficacy of chemotherapy in patients with advanced gastric cancer according to the RESIST standard and divided the patients into three groups: Complete remission (CR), partial remission (PR) and disease progression (PD). The characteristics of the expression of miR-146a were analyzed in 
Table III. Correlation between the expression of miR146a and LIN52.

\begin{tabular}{lcrrr}
\hline & & \multicolumn{2}{c}{ LIN52 } & \\
\cline { 3 - 4 } miR146a & $\mathrm{n}$ & Low, n(\%) & High, n (\%) & P-value \\
\hline Low & 49 & $21(42.9)$ & $28(57.1)$ & $<0.001$ \\
High & 44 & $36(81.8)$ & $8(18.2)$ & \\
\hline
\end{tabular}

miR146a was negatively associated with the expression of LIN52. ${ }^{a} \chi^{2}$ test. miR, microRNA.

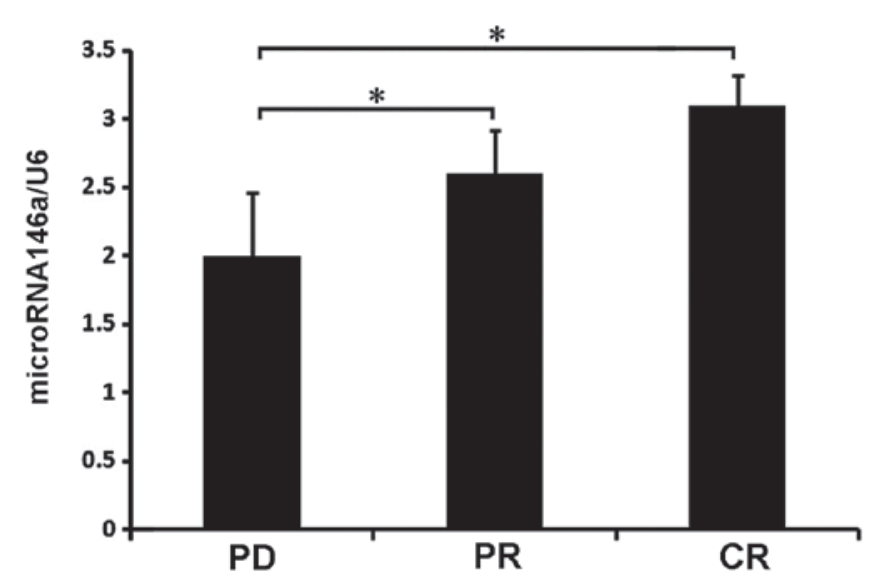

Figure 3. Expression of microRNA-146a is downregulated in gastric cancer tissues of chemotherapy-resistant patients (PD). * $\mathrm{P}<0.05$, compared with the $\mathrm{PD}$ group $(\mathrm{P}<0.05)$. $\mathrm{PD}$, progressive disease $\mathrm{PR}$, partial regression; $\mathrm{CR}$, complete remission.

the three groups. The expression of miR-146a in the CR group was the highest, with significant differences between the PR and PD groups, and the PR and PD groups $(\mathrm{P}<0.05)$, but not between the $\mathrm{PR}$ and $\mathrm{CR}$ groups $(\mathrm{P}>0.05)$.

Evaluation of diagnostic specificity and sensitivity of miR-146a in patients with advanced gastric cancer using ROC curve regression analysis. The area under the ROC curve of miR-146a in the advanced gastric cancer tissues and corresponding adjacent non-tumor tissue was 0.760 [5\% confidence interval $(\mathrm{CI})=0.589-0.942 ; \mathrm{P}=0.016]$, suggesting that miR-146a was significant for distinguishing between advanced gastric cancer tissue and normal tissue $(\mathrm{P}<0.05)$. Lower expression levels of miR-146a increased the likelihood of advanced gastric cancer. These results indicated the suitability of using miR-146a as an adjuvant diagnostic marker for advanced gastric cancer. In the present study, the relative expression of miR-146a was 19.75 , which was used as the evaluation threshold for the diagnosis of advanced gastric cancer, with $94.1 \%$ sensitivity and $61.5 \%$ specificity (Fig. 4).

\section{Discussion}

Gastric cancer is one of the most common types of cancer in China, with a high incidence rate and insidious early symptoms (12). At the time of diagnosis, patients with gastric cancer

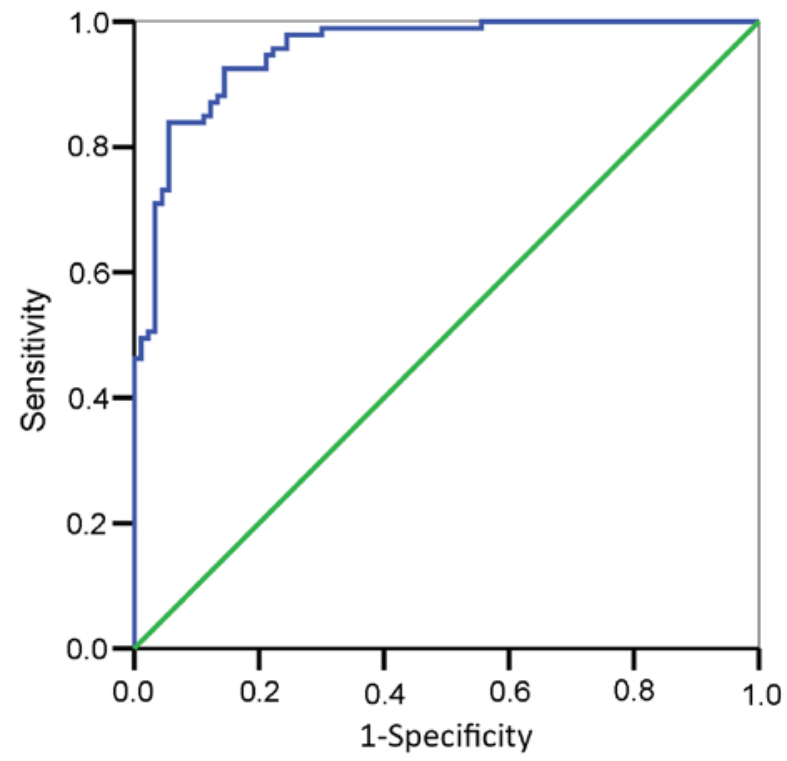

Figure 4. Sensitivity curve suggested for the diagnosis of gastric tumor tissue based on the $\mathrm{Cq}$ values of the relative expression of microRNA-146a in the tissues of patients.

are often at moderate and/or advanced stages of the disease, with poor prognosis (11). Therefore, the degree of malignancy and the mortality rates of patients with gastric cancer are relatively high. At present, there is no method for the effective early diagnosis of gastric cancer and, if diagnosed with an advanced stage of disease, radical surgery is not an option for patients. Advances in molecular targeted therapy and chemotherapies have not significantly improved the median survival rates of patients with advanced gastric cancer (13). Although $\alpha$-fetoprotein, carcinoembryonic antigen, CA125 and CA199 enhance the early diagnostic sensitivity of gastric cancer, their diagnostic specificities as markers of gastric cancer are low (14). It is necessary to investigate novel diagnostic markers for gastric cancer to provide guidance for cancer diagnosis and treatment (15). To address this problem, studies are focusing on the use of miRs in gastric cancer as potential biomarkers (16). Evaluation of the expression of $\mathrm{miR}$ in tumor tissue and patient serum is important in the early diagnosis and prognosis of gastric cancer (17). In the present study, the expression of miR-146a in gastric cancer tissue was correlated with the early diagnosis of gastric cancer and the prognosis of patients, and predictive analysis on these parameters was performed.

Through binding with the mRNA 3'-untranslated region (3'UTR), a single miR may have regulatory effects against various mRNAs. Typically, there is differential expression of miRs in tumor tissues, compared with normal tissues. miRs usually have specific and stable expression in tissues, therefore, miRs offer potential as prognostic markers $(18,19)$. Binding between miRs and the 3'UTR of mRNA suppresses mRNA transcription and affects the expression of oncogenes and tumor suppressor genes, thereby promoting or inhibiting tumor occurrence, development and metastasis. A previous study showed that miRs can be used as potential targets in anticancer therapy (20). Another prevopis study showed that miRs are associated with tumor metastasis, tolerance of anticancer therapy and tumor progression $(21,22)$. In addition, miRs have 
Table IV. Cox regression analysis of prognostic factors in patients with gastric cancer.

$95.0 \% \mathrm{CI}$ for HR

\begin{tabular}{lccccccc}
\cline { 4 - 7 } Factor & Regression coefficient & $\mathrm{SE}$ & $\chi^{2}$ & P-value $^{\mathrm{a}}$ & HR $^{\mathrm{a}}$ & Lower & Upper $^{-}$ \\
\hline TNM staging & 0.732 & 0.345 & 4.489 & 0.034 & 2.079 & 1.056 & 4.09 \\
Lymph node metastasis & -2.512 & 1.088 & 5.325 & 0.021 & 0.0081 & 0.010 & 0.685 \\
microRNA-146a expression & -2.048 & 0.785 & 6.806 & 0.009 & 0.129 & 0.028 & 0.601 \\
\hline
\end{tabular}

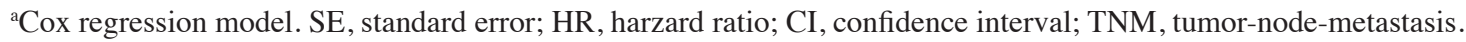

only 20 nucleotide bases, which facilitates its stable expression in tissues and its detection (23). Therefore, miRs have received increasing attention in tumor diagnosis, treatment evaluation and determining the prognosis of cancer $(24,25)$.

Although the biological functions of miRs remain to be fully elucidated, the expression of miR in normal tissue, compared with tumor tissue, is often apparent. To date, increasing applications of miRs as tissue-specific markers have become available for the analysis of primary tumor metastasis $(26,27)$. The present study showed that the relative expression of miR-146a in gastric cancer tissue was significantly lower, compared with that in the corresponding adjacent normal gastric mucosa, suggesting that miR-146a acted as a tumor suppressor gene. Early detection of the expression of miR-146a of gastric cancer may assist in the early diagnosis of the disease. In the present study, correlation analysis between the expression of miR-146a and relevant clinicopathological factors in gastric cancer showed that a low expression of miR-146a was significantly associated with lymph node metastasis in the patients. The relative expression of miR-146a in patients with advanced gastric cancer and lymph node metastasis was lower, compared with that in patients with advanced gastric cancer without lymph node metastasis. These results also suggested that miR-146a may act as a tumor suppressor, which increased the degree of malignancy and led to early metastasis of the tumor. As tumors progressed between early stages (stage I and II) and late stages (stage III and IV), the expression of miR-146a decreased, although no statistical significance was found. Previous studies also showed that the expression of miRs in patient tumor tissue had no significant correlation with the clinical staging of advanced gastric cancer $(28,29)$, which was also observed in tissue samples. Further studies are required to investigate the reasons behind this discrepancy. In the present study, the expression of miR-146a was correlated with patient survival rates, which was consistent with the findings of a previous study on gastric cancer (8). Compared with previous findings, the present study showed that the expression of miR-146a was associated with early diagnosis of gastric cancer, and also had specificity in the diagnosis of gastric cancer. The present study also found that the expression of miR-146a was associated with the efficacy of anticancer treatment. Patients with high expression levels of miR-146a in advanced gastric cancer tissues demonstrated a significantly higher treatment efficacy.

According to biological prediction, miR-146a binds to the 3'UTR of LIN52 to regulate the expression of LIN52 and affect LIN52 function. The immunohistochemical staining showed that the protein expression of LIN52 in advanced gastric cancer tissue was negatively correlated with the expression of miR-146a, suggesting that LIN52 was involved as an oncogene, compared with miR-146a. A previous study showed that inhibition of the expression of LIN52 in gastrointestinal stromal tumors promoted imatinib-induced apoptosis and was involved in tumor suppression (9). The present study found that the inhibition of LIN52 by miR-146a resulted in improved survival rates of the patients. Several drugs used for chemotherapy have poor efficacy against tumor cells at the G0 phase of the cell cycle. However, numerous tumor cells are at the G0 phase, which is also a major reason for the resistance to drug chemotherapy (30). The activation of LIN52 directly affects the cell cycle, allowing the majority of cells to remain at the G0 resting phase (31) and preventing the cells from entering the DNA synthesis phase ( $\mathrm{S}$ phase) (32). miR-146a inhibits the expression of LIN52 and reduces the number of cancer cells remaining in the $\mathrm{G} 0$ phase, thereby increasing the ratio of cancer cells at the $\mathrm{S}$ phase and improving the efficacy of anticancer therapy. A previous study showed that miRs affect the cell cycle of cancer cells, which may be one of the reasons they can affect the resistance of tumors to drugs (33). Although the present study showed that the expression of miR-146a was significantly correlated with the expression of LIN52 and with chemotherapeutic sensitivity, it is unclear whether miR-146a affects and reverses the effects of chemotherapy through LIN52 to regulate cancer cell cycle. Further investigations are required to verify these mechanisms.

Although miRs are promising markers in the diagnosis and prognosis of cancer, and dozens of miRs can be used for the diagnosis of gastric cancer $(34,35)$, there are several restrictions on methods and technical limitations in the clinical detection of miRs. Currently, several detection methods and software packages are available for miR detection in different types of cancer. However, standardized approaches are different, leading to inconsistent findings among studies (36). For this reason, it is necessary to develop standardized methods of assessment and introduce housekeeping miRs with stable expression, including miR-16 and RUN6B. For the detection of gastric cancer, serum miR-93 is recommended as a marker gene to identify healthy controls (37). Others have also suggested the use of miRs with low expression levels in humans but high expression in lower organisms, including Caenorhabditis elegans, as internal controls (38). With advancements in the future, microRNAs are likely to be of increased clinical use and offer more accurate guidance in cancer investigations. 


\section{Acknowledgements}

This study was supported by the Natural Science Foundation of China (grant no. U1504820).

\section{References}

1. Yang T, Zeng H, Chen W, Zheng R, Zhang Y, Li Z, Qi J, Wang M Chen T, Lou J, et al: Helicobacter pylori infection, H19 and LINC00152 expression in serum and risk of gastric cancer in a Chinese population. Cancer Epidemiol 44: 147-153, 2016.

2. Colquhoun A, Arnold M, Ferlay J, Goodman KJ, Forman D and Soerjomataram I: Global patterns of cardia and non-cardia gastric cancer incidence in 2012. Gut 64: 1881-1882, 2015.

3. Sempere LF: Integrating contextual miRNA and protein signatures for diagnostic and treatment decisions in cancer. Expert Rev Mol Diagn 11: 813-827, 2011.

4. Imam JS, Buddavarapu K, Lee-Chang JS, Ganapathy S, Camosy C, Chen Y and Rao MK: MicroRNA-185 suppresses tumor growth and progression by targeting the Six1 oncogene in human cancers. Oncogene 29: 4971-4979, 2010.

5. Jin ZW, Jiang W and Wang L: Biomarkers for gastric cancer: Progression in early diagnosis and prognosis (Review). Oncol Lett 9: 1502-1508, 2015.

6. Yao Q, Cao Z, Tu C,Zhao Y, Liu H and Zhang S: MicroRNA-146a acts as a metastasis suppressor in gastric cancer by targeting WASF2. Cancer Lett 335: 219-224, 2013

7. Hou Z, Xie L, Yu L, Qian X and Liu B: MicroRNA-146a is down-regulated in gastric cancer and regulates cell proliferation and apoptosis. Med Oncol 29: 886-892, 2012.

8. Kogo R, Mimori K, Tanaka F, Komune S and Mori M: Clinical significance of miR-146a in gastric cancer cases. Clin Cancer Res 17: 4277-4284, 2011.

9. Boichuk S, Parry JA, Makielski KR, Litovchick L, Baron JL, Zewe JP, Wozniak A, Mehalek KR, Korzeniewski N, Seneviratne DS, et al: The DREAM complex mediates GIST cell quiescence and is a novel therapeutic target to enhance imatinib-induced apoptosis. Cancer Res 73: 5120-5129, 2013.

10. Grimson A, Farh KK, Johnston WK, Garrett-Engele P, Lim LP and Bartel DP: MicroRNA targeting specificity in mammals: Determinants beyond seed pairing. Mol Cell 27: 91-105, 2007.

11. Jensen EH and Tuttle TM: Preoperative staging and postoperative surveillance for gastric cancer. Surg Oncol Clin N Am 16: 329-342, 2007

12. Duan X, Cao W, Wang L, Liu S, Liu Z, Zhang B, Yang H, Feng T, Zhang J, Zhang X, et al: Genetic variants in TERT are associated with risk of gastric cancer in a Chinese Han population. Oncotarget: Nov 4, 2016 (Epub ahead of print).

13. Takahashi TY, Saikawa Y and Kitagawa Y: Gastric cancer: Current status of diagnosis and treatment. Cancers (Basel) 5: 48-63, 2013.

14. Matsumoto K, Ueyama H, Matsumoto K, Akazawa Y, Komori H, Takeda T, Murakami T, Asaoka D, Hojo M, Tomita N, et al: Clinicopathological features of alpha-fetoprotein producing early gastric cancer with enteroblastic differentiation. World J Gastroenterol 22: 8203-8210, 2016.

15. He CZ, Zhang KH, Li Q, Liu XH, Hong Y and Lv NH: Combined use of AFP, CEA, CA125 and CA19-9 improves the sensitivity for the diagnosis of gastric cancer. BMC Gastroenterol 13: 87, 2013.

16. Wu WY, Xue XY, Chen ZJ, Han SL, Huang YP, Zhang LF, Zhu GB and Shen X: Potentially predictive microRNAs of gastric cancer with metastasis to lymph node. World J Gastroenterol 17: 3645-3651, 2011

17. Liu HS and Xiao HS: MicroRNAs as potential biomarkers for gastric cancer. World J Gastroenterol 20: 12007-12017, 2014.

18. Cui L, Zhang X, Ye G, Zheng T, Song H, Deng H, Xiao B, Xia T, Yu X, Le Y and Guo J: Gastric juice MicroRNAs as potential biomarkers for the screening of gastric cancer. Cancer 119: 1618-1626, 2013
19. Liu JL, Gao W, Kang QM, Zhang XJ and Yang SG: Prognostic value of survivin in patients with gastric cancer: A systematic review with meta-analysis. PLoS One 8: e71930, 2013.

20. Cerne JZ, Gersak K and Novakovic S: The influence of the genetic variant within miRNA-binding site in estrogen receptor alpha gene on the risk of breast cancer in postmenopausal women on hormone replacement therapy. Cancer Biomark 8: 123-128, 2010.

21. Kim BH, Hong SW, Kim A, Choi SH and Yoon SO: Prognostic implications for high expression of oncogenic microRNAs in advanced gastric carcinoma. J Surg Oncol 107: 505-510, 2013.

22. Wang J, Song YX and Wang ZN: Non-coding RNAs in gastric cancer. Gene 560: 1-8, 2015.

23. Zandberga E, Kozirovskis V, Ābols A, Andrējeva D, Purkalne G and Linē A: Cell-free microRNAs as diagnostic, prognostic, and predictive biomarkers for lung cancer. Genes Chromosomes Cancer 52: 356-369, 2013.

24. Verma M, Lam TK, Hebert E and Divi RL: Extracellular vesicles: Potential applications in cancer diagnosis prognosis, and epidemiology. BMC Clin Pathol 15: 6, 2015.

25. Migliore $\mathrm{C}$ and Giordano S: Resistance to targeted therapies: $A$ role for microRNAs? Trends Mol Med 19: 633-642, 2013.

26. Volinia S, Calin GA, Liu CG, Ambs S, Cimmino A, Petrocca F, Visone R, Iorio M, Roldo C, Ferracin M, et al: A microRNA expression signature of human solid tumors defines cancer gene targets. Proc Natl Acad Sci USA 103: 2257-2261, 2006.

27. Rosenfeld N, Aharonov R, Meiri E, Rosenwald S, Spector Y, Zepeniuk M, Benjamin H, Shabes N, Tabak S, Levy A, et al: MicroRNAs accurately identify cancer tissue origin. Nat Biotechnol 26: 462-429, 2008.

28. Li C, Li JF, Cai Q, Qiu QQ, Yan M, Liu BY and Zhu ZG: MiRNA-199a-3p: A potential circulating diagnostic biomarker for early gastric cancer. J Surg Oncol 108: 89-92, 2013.

29. Cai H, Yuan Y, Hao YF, Guo TK, Wei X and Zhang YM: Plasma microRNAs serve as novel potential biomarkers for early detection of gastric cancer. Med Oncol 30: 452, 2013.

30. Shah MA and Schwartz GK: Cell cycle-mediated drug resistance: An emerging concept in cancer therapy. Clin Cancer Res 7: 2168-2181, 2001.

31. Litovchick L, Florens LA, Swanson SK, Washburn MP and DeCaprio JA: DYRK1A protein kinase promotes quiescence and senescence through DREAM complex assembly. Genes Dev 25: 801-813, 2011.

32. Sadasivam SS, Duan S and DeCaprio JA: The MuvB complex sequentially recruits B-Myb and FoxM1 to promote mitotic gene expression. Genes Dev 26: 474-489, 2012.

33. Xie L, Jing R, Qi J, Lin Z and Ju S: Drug resistance-related microRNAs in hematological malignancies: Translating basic evidence into therapeutic strategies. Blood Rev 29: 33-44, 2015.

34. Rotkrua P, Shimada S, Mogushi K, Akiyama Y, Tanaka H and Yuasa Y: Circulating microRNAs as biomarkers for early detection of diffuse-type gastric cancer using a mouse model. $\mathrm{Br}$ J Cancer 108: 932-940, 2013.

35. Tsujiura M, Komatsu S, Ichikawa D, Shiozaki A, Konishi H, Takeshita H, Moriumura R, Nagata H, Kawaguchi $T$, Hirajima S, et al: Circulating miR-18a in plasma contributes to cancer detection and monitoring in patients with gastric cancer. Gastric Cancer 18: 271-279, 2015.

36. Tiberio P, Callari M, Angeloni V, Daidone MG and Appierto V: Challenges in using circulating miRNAs as cancer biomarkers. Biomed Res Int 2015: 731479, 2015.

37. Song J, Bai Z, Han W, Zhang J, Meng H, Bi J, Ma X, Han S and Zhang Z: Identification of suitable reference genes for qPCR analysis of serum microRNA in gastric cancer patients. Dig Dis Sci 57: 897-904, 2012.

38. Kroh EM, Parkin RK, Mitchell PS and Tewari M: Analysis of circulating microRNA biomarkers in plasma and serum using quantitative reverse transcription-PCR (qRT-PCR). Methods 50: 298-301, 2010. 